\title{
Strong convergence theorems for asymptotically nonexpansive nonself-mappings with applications
}

\author{
Weiping Guo', Afrah AN Abdou², Liaqat A Khan² and Yeol Je Cho $2,3^{*}$
}

\section{"Correspondence:}

aabdou@kau.edu.sa;

yjcho@gnu.ac.kr

${ }^{2}$ Department of Mathematics, King

Abdulaziz University, Jeddah, 21589,

Saudi Arabia

${ }^{3}$ Department of Mathematics Education and the RINS,

Gyeongsang National University, Chinju, 660-701, Korea

Full list of author information is

available at the end of the article

\begin{abstract}
In this paper, first, we introduce the condition (BP) which is weaker than the completely continuous mapping in Banach spaces. Second, we consider a simple iteration and prove some strong convergence theorems of the proposed iteration for an asymptotically nonexpansive nonself-mapping with the condition (BP). Finally, we give two examples to illustrate the main result in this paper. Our results improve and extend the corresponding results given by some authors.
\end{abstract}

Keywords: asymptotically nonexpansive nonself-mapping; strong convergence; fixed point; uniformly convex Banach space

\section{Introduction}

In 1972, Goebel and Kirk [1] introduced the class of asymptotically nonexpansive selfmappings.

Let $C$ be a nonempty subset of a real normed linear space $E$. A mapping $T: C \rightarrow C$ is said to be asymptotically nonexpansive if there exists a sequence $\left\{k_{n}\right\} \subset[1, \infty)$ with $\lim _{n \rightarrow \infty} k_{n}=1$ such that

$$
\left\|T^{n} x-T^{n} y\right\| \leq k_{n}\|x-y\|
$$

for all $x, y \in C$ and $n \geq 1$, and one proved the following.

Theorem GK If $C$ is a nonempty closed convex subset of a real uniformly convex Banach space $E$ and $T: C \rightarrow C$ is an asymptotically nonexpansive self-mapping, then $T$ has a fixed point in $C$.

On the other hand, in 1991, Schu [2] introduced the modified Mann process to approximate fixed points of an asymptotically nonexpansive self-mapping defined on a nonempty closed convex and bounded subset $C$ of a Hilbert space $H$ as follows:

Theorem JS Let H be a Hilbert space and $C$ be a nonempty closed convex bounded subset of $H$. Let $T: C \rightarrow C$ be a completely continuous and asymptotically nonexpansive mapping with the sequence $\left\{k_{n}\right\} \subset[1, \infty)$ with $\lim _{n \rightarrow \infty} k_{n}=1$ and $\sum_{n=1}^{\infty}\left(k_{n}^{2}-1\right)<\infty$. Let $\left\{\alpha_{n}\right\}$ be a real sequence in $[0,1]$ satisfying the condition $\varepsilon \leq \alpha_{n} \leq 1-\varepsilon$ for all $n \geq 1$ and for some $\varepsilon>0$.

(c) 2015 Guo et al. This article is distributed under the terms of the Creative Commons Attribution 4.0 International License (http://creativecommons.org/licenses/by/4.0/), which permits unrestricted use, distribution, and reproduction in any medium, provided you give appropriate credit to the original author(s) and the source, provide a link to the Creative Commons license, and indicate if changes were made. 
Then the sequence $\left\{x_{n}\right\}$ generated by

$$
\left\{\begin{array}{l}
x_{1} \in C \text { arbitrarily, } \\
x_{n+1}=\left(1-\alpha_{n}\right) x_{n}+\alpha_{n} T^{n} x_{n}
\end{array}\right.
$$

for each $n \geq 1$ converges strongly to some fixed point of $T$.

In Theorem JS, the mapping $T$ remains a self-mapping of a nonempty closed convex subset $C$ of a Hilbert space $H$. If, however, the domain $D(T)$ of $T$ is a proper subset of $H$ and $T: D(T) \rightarrow H$ is a mapping, the modified iteration $\left\{x_{n}\right\}$ defined by (JS) may fail to be well defined.

To overcome this situation, in 2003, Chidume et al. [3] introduced the concept of asymptotically nonexpansive nonself-mappings.

Let $E$ be a real Banach space. A subset $C$ of $E$ is called a retract of $E$ if there exists a continuous mapping $P: E \rightarrow K$ such that $P x=x$ for all $x \in C$. Every closed convex subset of a uniformly convex Banach space is a retract. A mapping $P: E \rightarrow E$ is called a retraction if $P^{2}=P$. It follows that, if a mapping $P$ is a retraction, then $P y=y$ for all $y$ in the range of $P$ (see [3]).

Definition 1.1 Let $C$ be a nonempty subset of a real normed linear space $E$. Let $P: E \rightarrow C$ be a nonexpansive retraction of $E$ onto $C$. A nonself-mapping $T: C \rightarrow E$ is said to be asymptotically nonexpansive if there exists a sequence $\left\{k_{n}\right\} \subset[1, \infty)$ with $\lim _{n \rightarrow \infty} k_{n}=1$ such that

$$
\left\|T(P T)^{n-1} x-T(P T)^{n-1} y\right\| \leq k_{n}\|x-y\|
$$

for all $x, y \in C$ and $n \geq 1$.

Also, Chidume et al. [3] introduced the following iteration scheme:

$$
\left\{\begin{array}{l}
x_{1} \in C \text { arbitrarily, } \\
x_{n+1}=P\left(\left(1-\alpha_{n}\right) x_{n}+\alpha_{n} T(P T)^{n-1} x_{n}\right)
\end{array}\right.
$$

for all $n \geq 1$, where $\left\{\alpha_{n}\right\} \subset(0,1)$, and proved some strong and weak convergence theorems for asymptotically nonexpansive nonself-mappings. We denote the set of fixed points of $T$ by $F(T)=\{x \in C: T x=x\}$.

Remark 1.1 If a mapping $T: C \rightarrow C$ is a self-mapping, then $P$ becomes the identity mapping and so we have the following:

(1) The nonself-mapping with (NSM) coincides with an asymptotically nonexpansive self-mapping.

(2) The iteration defined by (1.1) coincides with the iteration defined by (JS).

Since the results of Chidume et al., some authors proved weak and strong convergence theorems for asymptotically nonexpansive nonself-mappings in Banach spaces (see [4-7]).

Let $E$ be a real Banach space, $C$ be a nonempty closed convex subset of $E$ and $P: E \rightarrow C$ be a nonexpansive retraction of $E$ onto $E$. Let $T: C \rightarrow E$ be an asymptotically nonexpan- 
sive nonself-mapping. Now, we define the iterative scheme $\left\{x_{n}\right\}$ as follows:

$$
\left\{\begin{array}{l}
x_{1} \in C \text { arbitrarily, } \\
x_{n+1}=P\left(\left(1-\alpha_{n}\right) x_{n}+\alpha_{n} T(P T)^{n-1} y_{n}\right), \\
y_{n}=P\left(\left(1-\beta_{n}\right) x_{n}+\beta_{n} T(P T)^{n-1} x_{n}\right)
\end{array}\right.
$$

for all $n \geq 1$, where $\left\{\alpha_{n}\right\} \subset(0,1)$ and $\left\{\beta_{n}\right\} \subset[0,1]$.

In this paper, first, we introduce the condition (BP) which is weaker that the completely continuous mapping. Second, we introduce a new iteration (1.2) and prove some strong convergence theorems of the proposed iteration for an asymptotically nonexpansive nonself-mapping $T: C \rightarrow E$ with the condition (BP). Finally, we give two examples to illustrate the main result in this paper. Our results improve and extend the corresponding results given by some authors.

\section{Some lemmas}

For our main results, we need the following lemmas.

Lemma 2.1 ([8]) Let $p>1$ and $R>0$ be two fixed numbers and $X$ be a Banach space. Then $X$ is uniformly convex if and only if there exists a continuous, strictly increasing and convex function $g:[0, \infty) \rightarrow[0, \infty)$ with $g(0)=0$ such that

$$
\|\lambda x+(1-\lambda) y\|^{p} \leq \lambda\|x\|^{p}+(1-\lambda)\|y\|^{p}-\omega_{p}(\lambda) g(\|x-y\|)
$$

for all $x, y \in B(0, R)=\{x \in E:\|x\| \leq R\}$ and $\lambda \in[0,1]$, where $\omega_{p}(\lambda)=\lambda(1-\lambda)^{p}+\lambda^{p}(1-\lambda)$.

Letting $S_{1}=S_{2}=I$, where $I$ denotes the identity mapping, and $T_{1}=T_{2}=T$ in Lemma 3.1 of [4], we have the following.

Lemma 2.2 Let $E$ be a real uniformly convex Banach space and $C$ be a nonempty closed convex subset of $E$. Let $T: C \rightarrow E$ be an asymptotically nonexpansive nonself-mapping with $\left\{h_{n}\right\} \subset[1, \infty)$ such that $\sum_{n=1}^{\infty}\left(h_{n}-1\right)<\infty$ and $F(T) \neq \emptyset$. Let $\left\{x_{n}\right\}$ be the sequence defined by (1.2), where $\left\{\alpha_{n}\right\} \subset(0,1)$ and $\left\{\beta_{n}\right\} \subset[0,1)$. Then:

(1) $\left\|x_{n+1}-p\right\| \leq h_{n}^{2}\left\|x_{n}-p\right\|$ for all $p \in F(T)$;

(2) $\lim _{n \rightarrow \infty}\left\|x_{n}-p\right\|$ exists for all $p \in F(T)$.

Lemma 2.3 Let E be a real uniformly convex Banach space and $C$ be a nonempty closed convex subset of E. Let $T: C \rightarrow$ Ebe an asymptotically nonexpansive nonself-mapping with $\left\{h_{n}\right\} \subset[1, \infty)$ such that $\sum_{n=1}^{\infty}\left(h_{n}-1\right)<\infty$ and $F(T) \neq \emptyset$. Let $\left\{x_{n}\right\}$ be the sequence defined by (1.2), where

$$
0<\liminf _{n \rightarrow \infty} \alpha_{n}, \quad \limsup _{n \rightarrow \infty} \alpha_{n}<1
$$

and

$$
\limsup _{n \rightarrow \infty} \beta_{n}<1
$$

Then $\lim _{n \rightarrow \infty}\left\|x_{n}-T x_{n}\right\|=0$. 
Proof By Lemma 2.2, we know that $\lim _{n \rightarrow \infty}\left\|x_{n}-p\right\|$ exists for any $p \in F(T)$. It follows that $\left\{x_{n}-p\right\},\left\{y_{n}-p\right\},\left\{T(P T)^{n-1} x_{n}-p\right\},\left\{T(P T)^{n-1} y_{n}-p\right\}$ are all bounded, so there exists a real number $R>0$ such that

$$
\left\{x_{n}-p, y_{n}-p, T(P T)^{n-1} x_{n}-p, T(P T)^{n-1} y_{n}-p\right\} \subset B(0, R)
$$

for all $n \geq 1$. It follows from (1.2) and Lemma 2.1 that

$$
\begin{aligned}
\left\|y_{n}-p\right\|^{2} \leq & \left\|\left(1-\beta_{n}\right)\left(x_{n}-p\right)+\beta_{n}\left(T(P T)^{n-1} x_{n}-p\right)\right\|^{2} \\
\leq & \left(1-\beta_{n}\right)\left\|x_{n}-p\right\|^{2}+\beta_{n}\left\|T(P T)^{n-1} x_{n}-p\right\|^{2} \\
& -\beta_{n}\left(1-\beta_{n}\right) g\left(\left\|x_{n}-T(P T)^{n-1} x_{n}\right\|\right) \\
\leq & \left(1-\beta_{n}\right) h_{n}^{2}\left\|x_{n}-p\right\|^{2}+\beta_{n} h_{n}^{2}\left\|x_{n}-p\right\|^{2} \\
= & h_{n}^{2}\left\|x_{n}-p\right\|^{2}
\end{aligned}
$$

and so

$$
\begin{aligned}
\left\|x_{n+1}-p\right\|^{2} \leq & \left\|\left(1-\alpha_{n}\right)\left(x_{n}-p\right)+\alpha_{n}\left(T(P T)^{n-1} y_{n}-p\right)\right\|^{2} \\
\leq & \left(1-\alpha_{n}\right)\left\|x_{n}-p\right\|^{2}+\alpha_{n}\left\|T(P T)^{n-1} y_{n}-p\right\|^{2} \\
& -\alpha_{n}\left(1-\alpha_{n}\right) g\left(\left\|x_{n}-T(P T)^{n-1} y_{n}\right\|\right) \\
\leq & \left(1-\alpha_{n}\right) h_{n}^{4}\left\|x_{n}-p\right\|^{2}+\alpha_{n} h_{n}^{2}\left\|y_{n}-p\right\|^{2}-\alpha_{n}\left(1-\alpha_{n}\right) g\left(\left\|x_{n}-T(P T)^{n-1} y_{n}\right\|\right) \\
\leq & h_{n}^{4}\left\|x_{n}-p\right\|^{2}-\alpha_{n}\left(1-\alpha_{n}\right) g\left(\left\|x_{n}-T(P T)^{n-1} y_{n}\right\|\right),
\end{aligned}
$$

where $g:[0, \infty) \rightarrow[0, \infty)$ is a continuous strictly increasing and convex function with $g(0)=0$. By the conditions $0<\liminf _{n \rightarrow \infty} \alpha_{n}$ and $\lim \sup _{n \rightarrow \infty} \alpha_{n}<1$, we know that there exist a positive integer $n_{0}$ and two real numbers $a, b \in(0,1)$ such that $a \leq \alpha_{n} \leq b$ for all $n \geq n_{0}$, thus

$$
a(1-b) g\left(\left\|x_{n}-T(P T)^{n-1} y_{n}\right\|\right) \leq h_{n}^{4}\left\|x_{n}-p\right\|^{2}-\left\|x_{n+1}-p\right\|^{2}, \quad \forall n \geq n_{0} .
$$

Since $\lim _{n \rightarrow \infty}\left\|x_{n}-q\right\|$ exists, it follows from $\lim _{n \rightarrow \infty} h_{n}=1$ that

$$
\lim _{n \rightarrow \infty} g\left(\left\|x_{n}-T(P T)^{n-1} y_{n}\right\|\right)=0 .
$$

Using the properties of $g$, we have

$$
\lim _{n \rightarrow \infty}\left\|x_{n}-T(P T)^{n-1} y_{n}\right\|=0 .
$$

Since we have the conditions $\lim \sup _{n \rightarrow \infty} \beta_{n}<1$ and $\lim _{n \rightarrow \infty} h_{n}=1$, there exist a positive integer $m_{0}$ and a real number $s \in(0,1)$ such that $\beta_{n} h_{n} \leq s$ for all $n \geq m_{0}$ and

$$
\begin{aligned}
\left\|y_{n}-x_{n}\right\| & \leq \beta_{n}\left\|T(P T)^{n-1} x_{n}-x_{n}\right\| \\
& \leq \beta_{n}\left\|T(P T)^{n-1} x_{n}-T(P T)^{n-1} y_{n}\right\|+\beta_{n}\left\|x_{n}-T(P T)^{n-1} y_{n}\right\| \\
& \leq \beta_{n} h_{n}\left\|x_{n}-y_{n}\right\|+\left\|x_{n}-T(P T)^{n-1} y_{n}\right\| .
\end{aligned}
$$


Hence $(1-s)\left\|y_{n}-x_{n}\right\| \leq\left(1-\beta_{n} h_{n}\right)\left\|y_{n}-x_{n}\right\| \leq\left\|x_{n}-T(P T)^{n-1} y_{n}\right\|$ for all $n \geq m_{0}$. From (2.1), we have

$$
\lim _{n \rightarrow \infty}\left\|y_{n}-x_{n}\right\|=0
$$

Furthermore, from (2.1), (2.2), and

$$
\begin{aligned}
\left\|x_{n}-T(P T)^{n-1} x_{n}\right\| & \leq\left\|x_{n}-T(P T)^{n-1} y_{n}\right\|+\left\|T(P T)^{n-1} y_{n}-T(P T)^{n-1} x_{n}\right\| \\
& \leq\left\|x_{n}-T(P T)^{n-1} y_{n}\right\|+h_{n}\left\|y_{n}-x_{n}\right\|,
\end{aligned}
$$

it follows that

$$
\lim _{n \rightarrow \infty}\left\|x_{n}-T(P T)^{n-1} x_{n}\right\|=0
$$

It follows from (2.1) and

$$
\left\|x_{n+1}-T(P T)^{n-1} y_{n}\right\| \leq\left\|x_{n+1}-x_{n}\right\|+\left\|x_{n}-T(P T)^{n-1} y_{n}\right\| \leq\left(\alpha_{n}+1\right)\left\|x_{n}-T(P T)^{n-1} y_{n}\right\|
$$

that

$$
\lim _{n \rightarrow \infty}\left\|x_{n+1}-T(P T)^{n-1} y_{n}\right\|=0
$$

Since $\left\|x_{n+1}-y_{n}\right\| \leq\left\|x_{n+1}-T(P T)^{n-1} y_{n}\right\|+\left\|T(P T)^{n-1} y_{n}-x_{n}\right\|+\left\|x_{n}-y_{n}\right\|$, we have

$$
\lim _{n \rightarrow \infty}\left\|x_{n+1}-y_{n}\right\|=0
$$

by (2.1), (2.2) and (2.4). It follows from (2.3), (2.4), (2.5), and

$$
\begin{aligned}
\left\|x_{n}-T x_{n}\right\| \leq & \left\|x_{n}-T(P T)^{n-1} x_{n}\right\|+\left\|T(P T)^{n-1} x_{n}-T x_{n}\right\| \\
\leq & \left\|x_{n}-T(P T)^{n-1} x_{n}\right\|+\left\|T(P T)^{n-1} x_{n}-T(P T)^{n-1} y_{n-1}\right\| \\
& \quad+\left\|T(P T)^{n-1} y_{n-1}-T x_{n}\right\| \\
\leq & \left\|x_{n}-T(P T)^{n-1} x_{n}\right\|+h_{n}\left\|x_{n}-y_{n-1}\right\|+h_{1}\left\|T(P T)^{n-2} y_{n-1}-x_{n}\right\|
\end{aligned}
$$

that $\lim _{n \rightarrow \infty}\left\|x_{n}-T x_{n}\right\|=0$. This completes the proof.

\section{The condition (BP)}

Let $E$ be a Banach space and $T: E \rightarrow E$ be a bounded linear operator.

In 1966, Browder and Petryshyn [9] considered the existence of a solution of the equation

$$
u-T u=f
$$

by the iteration of Picard-Poincaré-Neumann,

$$
\left\{\begin{array}{l}
x_{0} \in E \text { arbitrarily, } \\
x_{n+1}=T x_{n}+f
\end{array}\right.
$$


equivalently,

$$
\left\{\begin{array}{l}
x_{0} \in E \text { arbitrarily, } \\
x_{n}=T^{n} x_{0}+\left(f+T f+\cdots+T^{n-1} f\right),
\end{array}\right.
$$

for each $n \geq 0$ and $f \in E$.

In fact, in 1958, Browder [10] proved the following.

Theorem B Let E be a reflexive Banach space. Then a solution $u$ of the equation $u-T u=f$ exists for a given point $f \in E$ and an operator $T$ which is asymptotically bounded (i.e., there exists $M \geq 0$ such that $\left\|T^{n} x\right\| \leq M$ for all $x \in E$ and $n \geq 1$ ) if and only if the sequence $\left\{x_{n}\right\}$ defined by (BP) is bounded for any fixed $x_{0} \in E$.

But, without any assumption of the reflexivity on $E$, under a slight sharper condition on $T$, Browder and Petryshyn proved the following:

Theorem BP Let E be a Banach space and $T: E \rightarrow E$ be a bounded linear operator which is asymptotically convergent, i.e., $\left\{T^{n} x\right\}$ converges in $E$ for all $x \in E$. Then we have the following:

(1) If $f \in R(I-T)$, the sequence $\left\{x_{n}\right\}$ defined by (BP) converges to a solution $u$ of the equation $u+T u=f$.

(2) If any subsequence $\left\{x_{n_{i}}\right\}$ of the sequence $\left\{x_{n}\right\}$ converges to an element $y \in E$, then $y$ is a solution of the equation $y-T y=f$.

(3) If $E$ is a reflexive Banach space and the sequence $\left\{x_{n}\right\}$ is bounded, then the sequence $\left\{x_{n}\right\}$ converges to a solution of the equation $u+T u=f$.

Motivated by Theorem BP, we have the concept of the condition (BP) as follows:

Let $E$ be a real normed linear space, $C$ be a nonempty subset of $E$ and $T: C \rightarrow E$ be a mapping.

Definition 3.1 The pair $(T, C)$ is said to satisfy the condition (BP) if, for any bounded closed subset $G$ of $C,\{z: z=x-T x, x \in G\}$ is a closed subset of $E$.

Let $E$ and $F$ be Banach spaces. Recall that a mapping $T: E \rightarrow F$ is completely continuous if it is continuous and compact (i.e., $C$ is bounded implies that $T(C)$ is relatively compact, i.e., $\overline{T(C)}$ is compact) or a weakly convergent sequence $\left(x_{n} \rightarrow x\right.$ weakly) implies a strongly convergent sequence $\left(T x_{n} \rightarrow T x\right)$.

We give some relations between the condition (BP) and a completely continuous mapping as follows.

Proposition 3.1 Let $E$ be a real normed linear space, $C$ be a nonempty subset of $E$ and $T: C \rightarrow$ E be a completely continuous mapping. Then the pair $(T, C)$ satisfies the condition (BP).

Proof For any bounded closed subset $G$ of $C$, we denote $M=\{z: z=x-T x, x \in G\}$. For any $z_{n} \in M$ with $z_{n} \rightarrow z$, there exists $x_{n} \in G$ such that $z_{n}=x_{n}-T x_{n}$. Since $T$ is completely continuous and the sequence $\left\{x_{n}\right\}$ is bounded, there exists a subsequence $\left\{x_{n_{k}}\right\}$ of $\left\{x_{n}\right\}$ such 
that $\left\{T x_{n_{k}}\right\}$ is convergent. Letting $T x_{n_{k}} \rightarrow x_{0}$, it follows that $x_{n_{k}}=z_{n_{k}}+T x_{n_{k}} \rightarrow z+x_{0}$ as $k \rightarrow \infty$. Since $G$ is closed, it follows that $z+x_{0} \in G$.

Furthermore, since $T$ is a completely continuous mapping, we have

$$
z=\lim _{k \rightarrow \infty} z_{n_{k}}=\lim _{k \rightarrow \infty}\left(x_{n_{k}}-T x_{n_{k}}\right)=\left(z+x_{0}\right)-T\left(z+x_{0}\right) .
$$

It follows from $z+x_{0} \in G$ that $z \in M$ and so $M$ is closed. This shows that the pair $(T, C)$ satisfies the condition (BP) and so Proposition 3.1 holds. This completes the proof.

Remark 3.1 If the pair $(T, C)$ satisfies the condition (BP), then $T$ is not completely continuous in general.

Example 3.1 Let $E=(-\infty, \infty)$ with the usual norm $|\cdot|$ and $C=\left\{0,1, \frac{1}{2}, \ldots\right\}$. Define a mapping $T: C \rightarrow E$ by

$$
T x= \begin{cases}0, & \text { if } x=0 \\ n, & \text { if } x=\frac{1}{n}, n \geq 1 .\end{cases}
$$

Then, for any bounded closed subset $G$ of $C$, the set $\{z: z=x-T x, x \in G\}^{d}=\emptyset$, where $A^{d}$ denotes the set of accumulation points of $A$, and so $\{z: z=x-T x, x \in G\}$ is a closed subset of $E$. This shows that the pair $(T, C)$ satisfies the condition (BP), but the set $T(C)=$ $\{0,1,2, \ldots, n, \ldots\}$ is unbounded. So, $T$ is not completely continuous.

\section{Strong convergence theorems}

Now, we prove strong convergence theorems for asymptotically nonexpansive nonselfmappings with the condition (BP) in real uniformly convex Banach spaces.

Theorem 4.1 Let E be a real uniformly convex Banach space and $C$ be a nonempty closed convex subset of $E$. Let $T: C \rightarrow E$ be an asymptotically nonexpansive nonself-mapping with $\left\{h_{n}\right\} \subset[1, \infty)$ such that $\sum_{n=1}^{\infty}\left(h_{n}-1\right)<\infty$ and $F(T) \neq \emptyset$. Let $\left\{x_{n}\right\}$ be the sequence defined by

$$
\left\{\begin{array}{l}
x_{1} \in C \text { arbitrarily, } \\
x_{n+1}=P\left(\left(1-\alpha_{n}\right) x_{n}+\alpha_{n} T(P T)^{n-1} y_{n}\right), \\
y_{n}=P\left(\left(1-\beta_{n}\right) x_{n}+\beta_{n} T(P T)^{n-1} x_{n}\right)
\end{array}\right.
$$

for all $n \geq 1$, where

$$
0<\liminf _{n \rightarrow \infty} \alpha_{n}, \quad \limsup _{n \rightarrow \infty} \alpha_{n}<1,
$$

and

$$
\limsup _{n \rightarrow \infty} \beta_{n}<1 .
$$

If the pair $(T, C)$ satisfies the condition (BP), then the sequence $\left\{x_{n}\right\}$ converges strongly to a fixed point of $T$.

Proof Letting $G=\overline{\left\{x_{n}\right\}}$, where $\overline{\left\{x_{n}\right\}}$ denotes the closure of $\left\{x_{n}\right\}$, since the sequence $\left\{x_{n}\right\}$ is bounded in $C$ by Lemma 2.2(2) and so $G$ is a bounded closed subset of $C$. Since the 
pair $(T, C)$ satisfies the condition (BP), it follows that $M=\{z=x-T x: x \in G\}$ is closed. From $\left\{x_{n}-T x_{n}\right\} \subset M$ and $x_{n}-T x_{n} \rightarrow 0$ as $n \rightarrow \infty$ by Lemma 2.3 , we know that the zero vector $0 \in M$ and so there exists a $q \in G$ such that $q=T q$. This shows that $q$ is a fixed point of $T$. Since $q \in G$, there exists a positive integer $n_{0}$ such that $x_{n_{0}}=q$ or there exists a subsequence $\left\{x_{n_{k}}\right\}$ of $\left\{x_{n}\right\}$ such that $x_{n_{k}} \rightarrow q$ as $k \rightarrow \infty$.

If $x_{n_{0}}=q$, then it follows from Lemma 2.2(1) that $x_{n}=q$ for all $n \geq n_{0}$ and so $x_{n} \rightarrow q$ as $n \rightarrow \infty$.

If $x_{n_{k}} \rightarrow q$, then, since $\lim _{n \rightarrow \infty}\left\|x_{n}-q\right\|$ exists, we have $x_{n} \rightarrow q$ as $n \rightarrow \infty$. This completes the proof.

Using Theorem 4.1 and Proposition 3.1, we have the following.

Corollary 4.1 Let E be a real uniformly convex Banach space and C be a nonempty closed convex subset of $E$. Let $T: C \rightarrow$ E be an asymptotically nonexpansive nonself-mapping with $\left\{h_{n}\right\} \subset[1, \infty)$ such that $\sum_{n=1}^{\infty}\left(h_{n}-1\right)<\infty$ and $F(T) \neq \emptyset$. Let $\left\{x_{n}\right\}$ be the sequence defined by (4.1), where

$$
0<\liminf _{n \rightarrow \infty} \alpha_{n}, \quad \limsup _{n \rightarrow \infty} \alpha_{n}<1,
$$

and

$$
\limsup _{n \rightarrow \infty} \beta_{n}<1 .
$$

If $T$ is completely continuous, then the sequence $\left\{x_{n}\right\}$ converges strongly to a fixed point of $T$.

Letting $\beta_{n}=0$ for all $n \geq 1$ in Theorem 4.1, we have the following.

Theorem 4.2 Let $E$ be a real uniformly convex Banach space and $C$ be a nonempty closed convex subset of $E$. Let $T: C \rightarrow E$ be an asymptotically nonexpansive nonself-mapping with $\left\{h_{n}\right\} \subset[1, \infty)$ such that $\sum_{n=1}^{\infty}\left(h_{n}-1\right)<\infty$ and $F(T) \neq \emptyset$. Let $\left\{x_{n}\right\}$ be the sequence defined by (1.1), where

$$
0<\liminf _{n \rightarrow \infty} \alpha_{n}, \quad \limsup _{n \rightarrow \infty} \alpha_{n}<1 .
$$

If the pair $(T, C)$ satisfies the condition (BP), then the sequence $\left\{x_{n}\right\}$ converges strongly to a fixed point of $T$.

Using Theorem 4.2 and Proposition 3.1, we obtain the following.

Corollary 4.2 Let $E$ be a real uniformly convex Banach space and $C$ be a nonempty closed convex subset of $E$. Let $T: C \rightarrow$ E be an asymptotically nonexpansive nonself-mapping with $\left\{h_{n}\right\} \subset[1, \infty)$ such that $\sum_{n=1}^{\infty}\left(h_{n}-1\right)<\infty$ and $F(T) \neq \emptyset$. Let $\left\{x_{n}\right\}$ be the sequence defined by (1.1), where

$$
0<\liminf _{n \rightarrow \infty} \alpha_{n}, \quad \limsup _{n \rightarrow \infty} \alpha_{n}<1 .
$$

If $T$ is completely continuous, then the sequence $\left\{x_{n}\right\}$ converges strongly to a fixed point of $T$. 
Remark 4.1 Theorem 4.2 and Corollary 4.2 improve and extend Theorem 3.7 in [3] and extend Theorem 1.5 in [2], Theorem 3.2 in [11] and the corresponding results in [12] to the setting of Banach spaces and the more general class of nonself-mappings.

\section{Examples}

Now, we give two examples to illustrate Theorem 4.1 as follows.

Proposition 5.1 ([6]) Let $X$ be a Hilbert space and $C=\{x \in X:\|x\| \leq r\}$, where $r>0$. Let $P: X \rightarrow C$ be a mapping defined by

$$
P x= \begin{cases}x, & \text { if } x \in C, \\ \frac{r x}{\|x\|}, & \text { if } x \in X-C .\end{cases}
$$

Then $P$ is a nonexpansive retraction of $X$ onto $C$.

Example 5.1 Let $X=R^{n}$ with the inner product $\langle x, y\rangle=\sum_{i=1}^{n} x_{i} y_{i}$ and the usual norm $\|x\|=$ $\left(\sum_{i=1}^{n} x_{i}^{2}\right)^{\frac{1}{2}}$, then $X$ is a Hilbert space. Let $C=\{x \in X:\|x\| \leq 1\}$. Define the mapping $P: X \rightarrow$ $C$ by

$$
P x= \begin{cases}x, & \text { if } x \in C, \\ \frac{x}{\|x\|}, & \text { if } x \in X-C .\end{cases}
$$

Then $P$ is nonexpansive retraction of $X$ onto $C$ by Proposition 5.1. Define a mapping $T$ : $C \rightarrow X$ by

$$
T x=\left(1-x_{1}, 0, \ldots, 0\right)
$$

for all $x=\left(x_{1}, x_{2}, \ldots, x_{n}\right) \in C$. Then we have

$$
\|T x-T y\|=\left\|\left(y_{1}-x_{1}, 0, \ldots, 0\right)\right\| \leq\|x-y\|
$$

for all $x=\left(x_{1}, x_{2}, \ldots, x_{n}\right), y=\left(y_{1}, y_{2}, \ldots, y_{n}\right) \in C$, which shows that $T$ is a nonexpansive nonself-mapping and so

$$
\left\|T(P T)^{2-1} x-T(P T)^{2-1} y\right\| \leq\|P(T x)-P(T y)\| \leq\|T x-T y\| \leq\|x-y\| .
$$

Suppose that

$$
\left\|T(P T)^{k-1} x-T(P T)^{k-1} y\right\| \leq\|x-y\|
$$

for $n=k$. Then, when $n=k+1$, we have

$$
\begin{aligned}
\left\|T(P T)^{(k+1)-1} x-T(P T)^{(k+1)-1} y\right\| & \leq\left\|(P T)^{(k+1)-1} x-(P T)^{(k+1)-1} y\right\| \\
& =\left\|P\left[T(P T)^{k-1} x\right]-P\left[T(P T)^{k-1} y\right]\right\| \\
& \leq\left\|T(P T)^{k-1} x-T(P T)^{k-1} y\right\| \\
& \leq\|x-y\| .
\end{aligned}
$$


It follows from the mathematical induction that $T$ is an asymptotically nonexpansive nonself-mapping with the sequence $\left\{h_{n}\right\}$ defined by $h_{n}=1$ for each $\geq 1$ and $F(T)=$ $\left\{\left(\frac{1}{2}, 0, \ldots, 0\right)\right\}$.

Now, we prove that the pair $(T, C)$ satisfies the condition (BP). For any closed subset $G$ of $C$, we denote $M=\{z=x-T x: x \in G\}$. Then $M$ is closed. Indeed, for any $z_{n} \in M$ with $z_{n} \rightarrow z$, there exists $x_{n} \in G$ such that $z_{n}=x_{n}-T x_{n}$. Since $G$ is bounded closed in $C$ and so $G$ is compact. Therefore, there exists a convergence subsequence $\left\{x_{n_{k}}\right\}$ of $\left\{x_{n}\right\}$. Letting $x_{n_{k}} \rightarrow x_{0}$ as $k \rightarrow \infty$, we have $x_{0} \in G$ and it follows from the continuous property of $T$ that

$$
z=\lim _{k \rightarrow \infty} z_{n_{k}}=\lim _{k \rightarrow \infty}\left(x_{n_{k}}-T x_{n_{k}}\right)=x_{0}-T x_{0} \in M
$$

For any given $x_{1} \in C$, define a sequence $\left\{x_{n}\right\}$ by

$$
\left\{\begin{array}{l}
x_{n+1}=P\left(\left(1-\alpha_{n}\right) x_{n}+\alpha_{n} T(P T)^{n-1} y_{n}\right), \\
y_{n}=P\left(\left(1-\beta_{n}\right) x_{n}+\beta_{n} T(P T)^{n-1} x_{n}\right)
\end{array}\right.
$$

for all $n \geq 1$, where $\left\{\alpha_{2 n-1}\right\}$ is defined by $\alpha_{2 n-1}=\frac{4}{5}+\frac{1}{6 n}$ for each $n \geq 1,\left\{\alpha_{2 n}\right\}$ is defined by $\alpha_{2 n}=\frac{1}{10}+\frac{1}{2 n}$ and $\left\{\beta_{n}\right\}$ is defined by $\beta_{n}=\frac{2 n}{3 n+2}$ for each $n \geq 1$. It is easy to prove

$$
\liminf _{n \rightarrow \infty} \alpha_{n}=\frac{1}{10}, \quad \limsup _{n \rightarrow \infty} \alpha_{n}=\frac{4}{5},
$$

and

$$
\limsup _{n \rightarrow \infty} \beta_{n}=\frac{2}{3}
$$

Hence all the conditions of Theorem 4.1 are satisfied and so $\left\{x_{n}\right\}$ converges strongly to the fixed point $\left(\frac{1}{2}, 0, \ldots, 0\right)$ of $T$.

Example 5.2 Let $X=l^{2}$ with the inner product $\langle x, y\rangle=\sum_{i=1}^{\infty} x_{i} y_{i}$ and the norm $\|x\|=$ $\left(\sum_{i=1}^{\infty} x_{i}^{2}\right)^{\frac{1}{2}}$. Then $X$ is a real infinite dimensional Hilbert space. Let $C=\{x \in X:\|x\| \leq 1\}$. Define the mapping $P: X \rightarrow C$ by

$$
P x= \begin{cases}x, & \text { if } x \in C \\ \frac{x}{\|x\|}, & \text { if } x \in X-C .\end{cases}
$$

Then $P$ is a nonexpansive retraction of $X$ onto $C$. Define a mapping $T: C \rightarrow X$ by

$$
T x=\left(-x_{1},-x_{2}, \ldots,-x_{i}, \ldots\right)
$$

for all $x=\left(x_{1}, x_{2}, \ldots, x_{i}, \ldots\right) \in C$. Then we have

$$
\begin{aligned}
\|T x-T y\| & =\left\|\left(y_{1}-x_{1}, y_{2}-x_{2}, \ldots, y_{i}-x_{i}, \ldots\right)\right\| \\
& =\left(\sum_{i=1}^{\infty}\left(y_{i}-x_{i}\right)^{2}\right)^{\frac{1}{2}} \\
& =\|x-y\|
\end{aligned}
$$


for all $x=\left(x_{1}, x_{2}, \ldots, x_{i}, \ldots\right), y=\left(y_{1}, y_{2}, \ldots, y_{i}, \ldots\right) \in C$ and so $T$ is nonexpansive and, using the same method as given in Example 5.1, we can prove that $T$ is an asymptotically nonexpansive mapping with the sequence $\left\{h_{n}\right\}$ defined by $h_{n}=1$ for each $n \geq 1$ and $F(T)=\{(0,0, \ldots)\}$.

Now, we prove that the pair $(T, C)$ satisfies the condition (BP) and $T$ is not completely continuous. In fact, for any closed subset $G$ of $C$, we denote $M=\{z=x-T x: x \in G\}$. For any $z^{(n)} \in M$ with $z^{(n)} \rightarrow z$ as $n \rightarrow \infty$, there exists $x^{(n)}=\left(x_{1}^{(n)}, x_{2}^{(n)}, \ldots, x_{i}^{(n)}, \ldots\right) \in G$ such that $z^{(n)}=x^{(n)}-T x^{(n)}=2 x^{(n)}$. It follows from $z^{(n)} \rightarrow z$ that $x^{(n)} \rightarrow \frac{1}{2} z$ as $n \rightarrow \infty$. Since $G$ is closed in $C$, it follows that $\frac{1}{2} z \in G$. From the continuous property of $T$, it follows that

$$
z=\lim _{n \rightarrow \infty} z^{(n)}=\lim _{n \rightarrow \infty}\left(x^{(n)}-T x^{(n)}\right)=\frac{1}{2} z-T\left(\frac{1}{2} z\right) \in M .
$$

This shows that the pair $(T, C)$ satisfies the condition (BP). Since $T(C)=C$ and the unit ball $C$ in infinite dimensional Hilbert space is not sequential compact, it follows that $T$ is not completely continuous.

For any given $x^{(1)} \in C$, define a sequence $\left\{x^{(n)}\right\}$ by

$$
\left\{\begin{array}{l}
x^{(n+1)}=P\left(\left(1-\alpha_{n}\right) x^{(n)}+\alpha_{n} T(P T)^{n-1} y^{(n)}\right), \\
y^{(n)}=P\left(\left(1-\beta_{n}\right) x^{(n)}+\beta_{n} T(P T)^{n-1} x^{(n)}\right)
\end{array}\right.
$$

for all $n \geq 1$, where $\left\{\alpha_{2 n-1}\right\}$ is defined by $\alpha_{2 n-1}=\frac{3}{5}+\frac{1}{4 n}$ for each $n \geq 1,\left\{\alpha_{2 n}\right\}$ is defined by $\alpha_{2 n}=\frac{1}{7}+\frac{1}{2 n}$ and $\left\{\beta_{n}\right\}$ is defined by $\beta_{n}=\frac{3 n}{4 n+2}$ for each $n \geq 1$. It is easy to prove

$$
\liminf _{n \rightarrow \infty} \alpha_{n}=\frac{1}{7}, \quad \limsup _{n \rightarrow \infty} \alpha_{n}=\frac{3}{5}
$$

and

$$
\limsup _{n \rightarrow \infty} \beta_{n}=\frac{3}{4}
$$

Hence all the conditions of Theorem 4.1 are satisfied and so $\left\{x^{(n)}\right\}$ converges strongly to the fixed point $(0,0, \ldots)$ of $T$. Since $T$ is not completely continuous, the above conclusions cannot be obtained by Theorem 3.1 in [4].

Competing interests

The authors declare that they have no competing interest.

Authors' contributions

All authors read and approved the final manuscript.

\section{Author details}

'School of Mathematics and Physics, Suzhou University of Science and Technology, Suzhou, Jiangsu 215009, P.R. China. ${ }^{2}$ Department of Mathematics, King Abdulaziz University, Jeddah, 21589, Saudi Arabia. ${ }^{3}$ Department of Mathematics Education and the RINS, Gyeongsang National University, Chinju, 660-701, Korea.

\section{Acknowledgements}

This project was funded by the Deanship of Scientific Research (DSR), King Abdulaziz University, under grant no. (18-130-36-HiCi). The authors, therefore, acknowledge with thanks DSR technical and financial support. Also, this project (WP Guo) was supported by the National Natural Science Foundation of China (Grant Number: 11271282) and the third author (YJ Cho) was supported by Basic Science Research Program through the National Research Foundation of Korea (NRF) funded by the Ministry of Science, ICT and future Planning (2014R1A2A2A01002100). 
References

1. Goebel, K, Kirk, WA: A fixed point theorem for asymptotically nonexpansive mapping. Proc. Am. Math. Soc. 35 171-174 (1972)

2. Schu, J: Iteration construction of fixed points of asymptotically nonexpansive mappings. J. Math. Anal. Appl. 158, 407-413 (1991)

3. Chidume, $\mathrm{CE}$, Ofoedu, EU, Zegeye, $\mathrm{H}$ : Strong and weak convergence theorems for asymptotically nonexpansive mappings. J. Math. Anal. Appl. 280, 364-374 (2003)

4. Guo, W, Cho, YJ, Guo, W: Convergence theorems for mixed type asymptotically nonexpansive mappings. Fixed Point Theory Appl. 2012, 224 (2012)

5. Guo, W, Guo, W: Weak convergence theorems for asymptotically nonexpansive nonself-mappings. Appl. Math. Lett. 24, 2181-2185 (2011)

6. Liu, YQ, Guo, W: Convergence theorems of composite implied iteration scheme for mixed type asymptotically nonexpansive mappings. Acta Math. Sci. A 35(2), 422-440 (2015)

7. Wang, L: Strong and weak convergence theorems for common fixed points of nonself asymptotically nonexpansive mappings. J. Math. Anal. Appl. 323, 550-557 (2006)

8. Xu, HK: Inequalities in Banach spaces with applications. Nonlinear Anal. 16, 1127-1138 (1991)

9. Browder, FE, Petryshyn, WV: The solution by iteration of linear functional equations in Banach spaces. Bull. Am. Math. Soc. 72, 566-570 (1966)

10. Browder, FE: On the iteration of transformations in noncompact minimal dynamical systems. Proc. Am. Math. Soc. 9 , 773-780 (1958)

11. Shahzad, N: Approximating fixed points of non-self nonexpansive mappings in Banach spaces. Nonlinear Anal. 61, 1031-1039 (2005)

12. Osilike, MO, Aniagbosor, SC: Weak and strong convergence theorems for fixed points of asymptotically nonexpansive mappings. Math. Comput. Model. 256, 431-445 (2001)

\section{Submit your manuscript to a SpringerOpen ${ }^{\circ}$ journal and benefit from:}

- Convenient online submission

Rigorous peer review

- Immediate publication on acceptance

- Open access: articles freely available online

- High visibility within the field

- Retaining the copyright to your article 